\title{
The Effects of Proanthocyanidin on Vasospasm After Experimental Subarachnoidal Hemorrhage in Rats
}

\author{
Cem YILMAZ1 ${ }^{1}$, Tufan CANSEVER ${ }^{1}$, Atilla KIRCELLI', Ozlem ISIKSACAN OZEN² ${ }^{2}$ Fatih AYDEMIR ${ }^{1}$, Aykan AKAR ${ }^{3}$, \\ Hakan CANER ${ }^{1}$ \\ 'Baskent University, Faculty of Medicine, Department of Neurosurgery, Ankara, Turkey \\ ${ }^{2}$ Baskent University, Faculty of Medicine, Department of Pathology, Ankara, Turkey \\ ${ }^{3}$ Gelisim Hospital, Neurosurgery Clinic, Iskenderun, Hatay, Turkey
}

\section{ABSTRACT}

AIM: Delayed ischemic neurological deficit (DIND) and cerebral vasospasm (CV) remain the most common and debilitating neurological complications following aneurysmal subarachnoidal hemorrhage (SAH). Many reports demonstrate the importance of proanthocyanidins (PR) on the vascular system, including endothelium-dependent relaxation of blood vessels. These effects of PR on the cerebral vascular system were examined in this study.

MATERIAL and METHODS: Fifty-two adult Sprague-Dawley male rats were used for the experimental double hemorrhage model. They were divided to control, sham, pre- and post-interventional treatment groups. $100 \mathrm{mg} / \mathrm{kg}$ PR was administered for the treatment for respect to groups. Basilar artery diameter (BAD) and arterial wall thickness were measured and the apoptosis ratio of the endothelial cells was calculated. Arterial walls were examined electron microscopically (EM).

RESULTS: There were significant differences between the groups except control and pre-SAH ( $p=0.37$ ) and post-SAH and preSAH groups $(p=0.15)$ with respect to BAD. According to arterial wall thickness, apoptosis ratio, and grading, there were significant differences between the groups except control and pre-SAH $(p=0.85, p=0.49$ and $p=0.18$ respectively) and SAH and post-SAH $(p=0.08, p=0.21$ and $p=0.24$ respectively) groups. EM findings revealed that pro-apoptotic and pro-necrotic degenerated endothelial cells with seldom vacuolization in post-SAH treatment group which were more serious in SAH group.

CONCLUSION: Pre-SAH administration of PR induces better vasodilatation and protection of basilar artery (BA) from vasospasm (VS), which could yield neuroprotective and vasodilatator effects. In addition, PR appears to be involved in relieving oxidative damage, with an antioxidant-antiapoptotic-antinecrotic effect that may contribute to vascular dilation.

KEYWORDS: Subarachnoidal hemorrhage, Vasospasm, Proanthocyanidin, Antioxidant, Rats

\section{INTRODUCTION}

$\mathrm{D}$ elayed ischemic neurological deficit (DIND) and cerebral vasospasm (CV) remain the most common and debilitating neurological complications following subarachnoid hemorrhage (SAH) (37). Twenty-five to $30 \%$ of patients who survive SAH from a ruptured intracranial aneurysm suffer from ischemic complications in the ensuing weeks, and 10 to $15 \%$ of patients with SAH die or experience permanent disability due to their ischemic deficits $(18,21)$.
Although there is some controversy regarding the correlation between cerebral vasospasm in large arteries and cerebral ischemia, vasospasm remains one of the primary causes of DIND $(25,35)$. Proven therapeutic options for the treatment and/or prevention of DIND or CV are few. Suarez et al., summarized current treatment recommendations for vasospasm as consisting of prophylactic nimodipine; hypervolemia with induced hypertension, usually following the onset of vasospasm with neurological deficits; and a potential for balloon 
angioplasty or directed application of vasodilating agents (37). Due to the emergence of the more rigorous principles of evidence-based medicine, the need has arisen for a review of the available evidence on which to base the prevention and treatment of vasospasm in patients suffering from aneurysmal $\mathrm{SAH}$.

Proanthocyanidins (PR) are plant condensed tannins with known properties of antimicrobial, antiviral, antitumoral, antioxidant, anti-inflammatory, antiulcer, and anti-diarrheal activity (12). Their regulatory effects on the cardiovascular system have also been demonstrated. These regulatory effects mainly include decreasing expression of VCAM-1, ICAM-1, and E-selectins induced by tumor necrosis factor-a (TNF-a) and limiting platelet aggregation. Proanthocyanidins also have an effect on nitric oxide (NO) and NO synthase (NOS) activity that are believed to have a very important role in the cerebral vasospasm mechanism (12).

The endogenous NOS (eNOS) activity is regulated by mechanisms such as expression and transcription of NOS, subcellular localization (protein-protein interactions and acylation of eNOS), regulation of NOS enzymatic activity by effects on the NOS protein (calcium/calmodulin and reversible palmitoylation), phosphorylation, and S-nitrosylation $(14,15)$. Intracellular calcium is increased by mobilization from the stores and also $\mathrm{Ca} 2+$ entry via voltage-independent cation channels and this results in activation of eNOS $(4,5,13,23)$.

Phospholipase C (PLC), phospholipase A2 (PLA2), tyrosine kinase, or protein kinase $(\mathrm{PKC})$ activities are also reported to be associated with the increase of $\mathrm{Ca} 2+(1,2)$.

The aim of this study was to evaluate the PR-induced vasodilator and antioxidant effect in the rat basilar artery after experimental vasospasm.

\section{MATERIAL and METHODS}

The Animal Care and Use Committee Institution at Baskent University approved the protocol for this study. The rat double hemorrhage model was used for inducing vasospasm $(36,39)$.

Male Sprague-Dawley rats $(n=52)$ each weighing 380 to 420 $\mathrm{g}$ were anesthetized by intraperitoneal injection of ketamine (Ketalar, Parke-Davis, Eczacibasi, Istanbul,Turkey) $(100 \mathrm{mg} /$ $\mathrm{kg}$ ) and xylazine (Rompun, Bayer, Istanbul, Turkey) (10 mg/ $\mathrm{kg}$ ). The animals were allowed to breathe spontaneously in the supine position and their body temperature was set to approximately $37^{\circ} \mathrm{C}$ by using heating pads. The inguinal region was prepared in a standard sterile manner, and the right femoral artery was exposed so that arterial blood could be obtained by cannulation. A suboccipital incision was made and nuchal muscles were divided bilaterally in order to expose the atlantooccipital membrane. A 26 -gauge needle was inserted into the cistern magna via an atlantooccipital membrane puncture and $0.2-0.3 \mathrm{ml}$ of cerebrospinal fluid (CSF) was aspirated. Then $0.2 \mathrm{ml}$ of non-heparinized autologous arterial blood was withdrawn from the femoral artery and injected into the cisterna magna over 2 minutes to simulate SAH. Sham group rats were injected with saline instead of blood.
After injection, the muscles and the skin incision were sutured in layers. The rats were placed in a head-down position for 20 minutes to ensure rostroventral blood distribution around the basal intracranial arteries. The rats remained on the heating pad and were monitored closely until they recovered. After the recovery, $100 \mathrm{mg} / \mathrm{kg}$ PR was initiated to the treatment groups.

The second SAH was induced with the same procedure on the second day with the sham group receiving saline again. The rats were randomly divided into four groups, each having 13 animals:

1. For control $(n=13), 0.2 \mathrm{~mL}$ of $0.9 \% \mathrm{NaCl}$ was injected into the subarachnoid space via puncture of the cisterna magna.

2. For the sham group $(n=13), 0.2 \mathrm{~mL}$ of autologous arterial blood was injected into the subarachnoid space via puncture of the cisterna magna.

3. For the post-interventional treatment group $(n=13)$, $0.2 \mathrm{~mL}$ of autologous arterial blood was injected into the subarachnoid space via puncture of the cisterna magna and $100 \mathrm{mg} / \mathrm{kg}$ PR was initiated orally (with gavage feeding tube) after the recovery of the rats from anesthesia and continued for five days at $100 \mathrm{mg} / \mathrm{kg} /$ day.

4. For the pre-interventional treatment group $(n=13), 100 \mathrm{mg} /$ $\mathrm{kg}$ PR was initiated orally (with gavage feeding tube) 24 hours before the surgical intervention and $0.2 \mathrm{~mL}$ of autologous arterial blood was injected into the subarachnoid space via puncture of the cisterna magna and $100 \mathrm{mg} / \mathrm{kg}$ PR was administered after the recovery of the rats from anesthesia and was continued for five days at $100 \mathrm{mg} / \mathrm{kg} /$ day.

\section{PR Preparation:}

We dissolved PR in $2 \mathrm{ml}$ water.

\section{Sacrificing of Animals and Sample Preparation}

Five days after the second cisterna magna puncture, 8 rats from surgical groups were sacrificed in deep anesthesia and underwent perfusion-fixation by thoracotomy. The ascending aorta was cannulated, perfusion fixation via intracardiac infusion of $100 \mathrm{~mL}$ of $0.03 \mathrm{M}$ phosphate buffer $(\mathrm{pH} 7.4)$, pre-warmed to $37^{\circ} \mathrm{C}$, and set up at a height of $100 \mathrm{~cm}$ was initiated, followed by $200 \mathrm{~mL}$ of $4 \%$ paraformaldehyde and $1 \%$ glutaraldehyde in phosphate buffer.

The brains of the animals were removed carefully after craniectomy and harvested basilar arteries were placed in paraformaldehyde and $1 \%$ glutaraldehyde in phosphate buffer solution and stored at $+4^{\circ} \mathrm{C}$. Paraffin-embedded tissues were cut at a thickness of 0.5 micrometers and stained with Hematoxylin and eosin (HE) and terminal deoxynucleotidyl transferasemediated deoxyuridine triphosphate biotin nick end labeling (TUNEL) staining was performed in order to show apoptosis.

Measuring the arterial diameter: Multiple arterial crosssections were obtained from each animal and after excluding irregular shapes, five specimens were randomly selected. The specimens were studied by a pathologist using ocular micrometer $(x 20,0.05 \mathrm{~mm}, 0.5 \mathrm{~mm})$ in order to measure the luminal cross-sectional areas. An average of the five measured 
specimens was calculated for each animal. Group data were shown as mean \pm standard error.

Staining for apoptosis: Immunohistology using the In Situ Cell Death Detection Kit, POD (Roche, Germany) was used to demonstrate apoptosis in a cross section of basilar arteries. Paraffin embedded samples were deparaffinized and rehydrated in decreasing concentrations of alcohol. Samples were first treated with proteinase $\mathrm{K}(20 \mathrm{mg} / \mathrm{mL})$ for 15 minutes at room temperature to increase permeability of the samples. After endogenous peroxidase activity was blocked with $3 \%$ $\mathrm{H}_{2} \mathrm{O}_{2}$ for 5 minutes, $75 \mu \mathrm{l}$ of equilibration buffer was applied on the sections. The samples were then treated with TUNEL reaction mixture, which catalyzes polymerization of nucleotides to free 39-OH DNA ends in a template independent manner, used to label DNA strand breaks, in a humidified chamber for 1 hour at RT. Sections were then incubated with ConverterPOD for $30 \mathrm{~min}$. and then to develop color, 3-Amino-9ethylcarbazole (AEC) was applied for $12 \mathrm{~min}$. Next, they were counterstained with methyl green and mounted. Between steps, the slides were washed in phosphate-buffered saline (PBS). Sections of the arteries showed staining in the nuclei of the endothelial cells. Apoptotic index was calculated as the number of the immunoreactive nuclei per total number of endothelial cells, expressed as a percentage.

Grading of the apoptosis: Apoptosis in basilar artery endothelial cells was evaluated. The ratio of the cells with positive nuclear staining to all endothelial cells in one section was calculated. Thus, approximately 80 endothelial cells were counted in every artery. The grading was established according to the percentages of the apoptotic cells (Grade 1: 0-25\%; Grade 2: 25-50\%; Grade 3: 50-75\%; Grade 4: 75100\%)

For transmission electron microscopy (TEM), three specimens from the surgical groups were placed in buffered $1 \%$ osmium tetroxide, dehydrated in a graded ethanol series and then embedded in Epon 821. They were examined under a JEOL $100 \mathrm{C}$ transmission electron microscope (JEOL Inc., Tokyo, Japan). For scanning electron microscopy (SEM), specimens were placed in cacodylate-buffered $2.5 \%$ glutaraldehyde for 3 $\mathrm{h}$ and post-fixed in $1 \%$ osmium tetroxide in the same buffer for $1 \mathrm{~h}$. They were then dehydrated in a graded alcohol series and amyl acetate and critical-point dried with $\mathrm{CO}_{2}$, coated with gold in an evaporator and examined under a JEOL scanning electron microscope.

\section{Statistical Analysis}

We measured the differences of mean values (arterial diameter, arterial wall thickness and apoptosis grading and ratio) analyzed with one-way variance analysis (One-Way ANOVA) and post hoc Tukey test. A "p" value of less than 0.05 was considered statistically significant. Results were expressed as mean, standard deviation (SD), median and range.

\section{- RESULTS}

Three animals from SAH and one from the post-treatment groups died on the $2^{\text {nd }}$ day of the operation and were excluded from study and replaced with new subjects. The macroscopic examination showed clot covering the brain stem and basal cistern of the subjects. Sections of basilar arteries demonstrated the differences in the diameter and wall-thickness of basilar arteries from each group under light microscopic evaluation (Figure 1A-D).

Luminal Diameters and Thickness: The measurements of luminal diameters and thickness are seen in Figure 3 and Table I. According to the measurements and assuming the luminal diameter there were significant differences between the groups except control and pre-SAH $(p=0.37)$ and post$\mathrm{SAH}$ and pre-SAH groups $(\mathrm{p}=0.15)$.

According to the measurements and assuming the arterial wall thickness there were significant differences between the groups except control and pre-SAH $(p=0.85)$ and post-SAH and SAH groups $(p=0.08)$.

According to apoptosis ratio and grading there were significant differences between the groups except control and pre-SAH $(p=0.49$ and $p=0.18)$ and SAH and post SAH $(p=0.21$ and $\mathrm{p}=0.24)$ groups.

Electron Microscopy Findings: Normal basilar artery lumen was seen in control group (Figure 2A). Electron microscopy revealed vacuolization of the endothelial cells in the tunica

Table I: According to the Measurements and Assuming the Luminal Diameter There were Significant Differences Between the Groups Except the Control-Pre-SAH and Post-SAH-Pre-SAH Groups. According to Arterial Wall Diameter, Apoptosis Ratio and Grading There were Significant Differences Between the Groups Except the Control-Pre-SAH and SAH-Post SAH Groups

\begin{tabular}{lcccc}
\hline Compared groups & $\begin{array}{c}\text { Arterial Diameter } \\
(\mathbf{p})\end{array}$ & $\begin{array}{c}\text { Arterial Wall Thickness } \\
(\mathbf{p})\end{array}$ & $\begin{array}{c}\text { Apoptosis Ratio } \\
(\mathbf{p})\end{array}$ & $\begin{array}{c}\text { Apoptosis Grade } \\
(\mathbf{p})\end{array}$ \\
\hline SAH-Control & $<0.0001$ & 0.001 & 0.008 & 0.009 \\
\hline SAH-post-SAH & 0.030 & 0.080 & 0.213 & 0.242 \\
\hline SAH-pre-SAH & 0.023 & 0.002 & 0.036 & 0.05 \\
\hline Control-post-SAH & 0.027 & 0.034 & 0.046 & 0.034 \\
\hline Control-pre-SAH & 0.371 & 0.847 & 0.494 & 0.178 \\
\hline post-SAH-pre-SAH & 0.154 & 0.019 & 0.034 & 0.070 \\
\hline
\end{tabular}


intima layer with the expression of lamellar shaped myelin figures, loosening and degeneration of internal elastic layer, irregularity and irregular extension of endothelial cells and tight, irregular and flat extensions between the endothelial cells in the SAH group (Figure 2B).

Even pro-apoptotic and pro-necrotic degenerated endothelial cells with seldom vacuolization can be seen in post-SAH treatment group. However normal endothelial cells and internal elastic membrane were seen mostly (Figure 2C).

\section{DISCUSSION}

After the investigation of the pathophysiology of cerebral vasospasm in numerous studies, the prevalent ideas about the mechanism are altered calcium homeostasis and increased vascular contractility. Its believed that the first step is the elevation of intracellular calcium levels in the arterial smooth muscle cells, and that hemoglobin $(\mathrm{Hb})$ is responsible for this increased calcium $(19,38)$. The responsibility of ferrous hemoglobin released from blood clots to the vasospasm was shown before, but this effect was temporary $(8,22,41)$.

Actually hemoglobin might show its contractile effect by scavenging nitric oxide, destroying neuronal nitric oxide synthase (NOS) in the adventitia layer and disturbing the function of endothelial NOS $(24,28,32)$. Prolonged decrease of NO can cause prolonged pathological arterial contraction independent from intracellular calcium concentration. Endothelins are also stimulated by hemoglobin resulting in a nitric oxide and endothelin imbalance $(16,28)$. Many clinical and experimental studies were performed about the endothelin receptor antagonist mechanism but they were inconclusive and did not lead to a reduction in the mortality and morbidity of $\mathrm{SAH}(27)$.

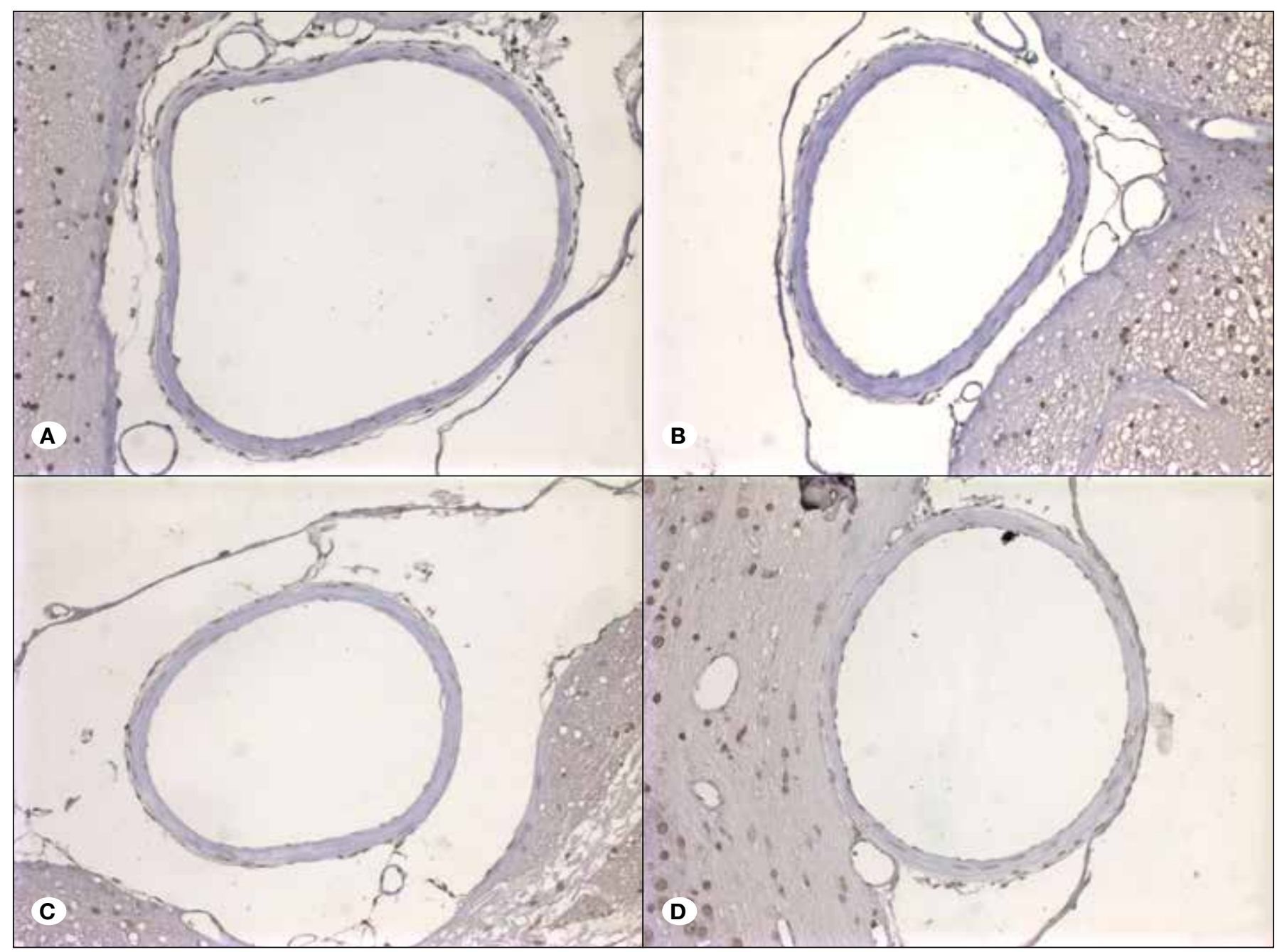

Figure 1: A) The lumens of the basilar arteries in the control group were covered by a simple lining of endothelial cells. The tunica media consisted of well-arranged smooth muscle cells. The tunica adventitia contained loosely arranged connective tissue cells. B) There was marked curling and thickening in the elastic lamina and swelling in the endothelial cells of the basilar arteries from the SAH groups. Endothelial cell membranes were cigar-like in shape and there were separations between neighboring elastic laminas. Smooth muscle cells in tunica media demonstrated swelling, thickening, shortening and vacuolization. C) In the post-treatment groups, there was mild curling and prominence of the elastic lamina and mild swelling of endothelial cells. D) The endothelial cell membrane kept its normal shape. Smooth muscle cells in the media layer demonstrated shortening and thickening and mild vacuolization. 
The early phase of the vasospasm after SAH was determined to shos increased intracranial pressure, disruption of the bloodbrain barrier (BBB), global cerebral ischemia, inflammation and cortical spreading depression $(17,26,29,34)$. These phases can cause delayed arterial narrowing in determining poor outcome following SAH in the late phase (22). As shown in our study, vasospasm is not only the contraction of the arterial wall. Electron microscopy revealed vacuolization of the endothelial cells in the tunica intima layer with the expression of lamellar shaped myelin figures, loosening and degeneration of internal elastic layer, irregularity and irregular extension of endothelial cells and tight, irregular and flat extensions between the endothelial cells. There were pro-apoptotic or pro-necrotic degenerated endothelial cells in the SAH and treatment groups at different levels. This degeneration can be established in every cerebral artery, which can be surrounded by CSF, which is filled with $\mathrm{Hb}$ brake-down products.

PRs, or plant condensed tannins, consist of a group of polyhydroxyl-flavan-3-ol (or flavan-3,4-diol) oligomers and polymers linked by carbon-carbon bonds between flavanol subunits. They are the second most abundant natural phenolic compound class after lignins (30). They are widely found in fruits, wine, cocoa, nuts, berries and beans and therefore consumed extensively by humans (30).

Vegetable tannins are also used in many medicinal plants used for a range of diseases. In a recent review by De Bruyne et al. several properties such as antimicrobial, antiviral, antitumoral,

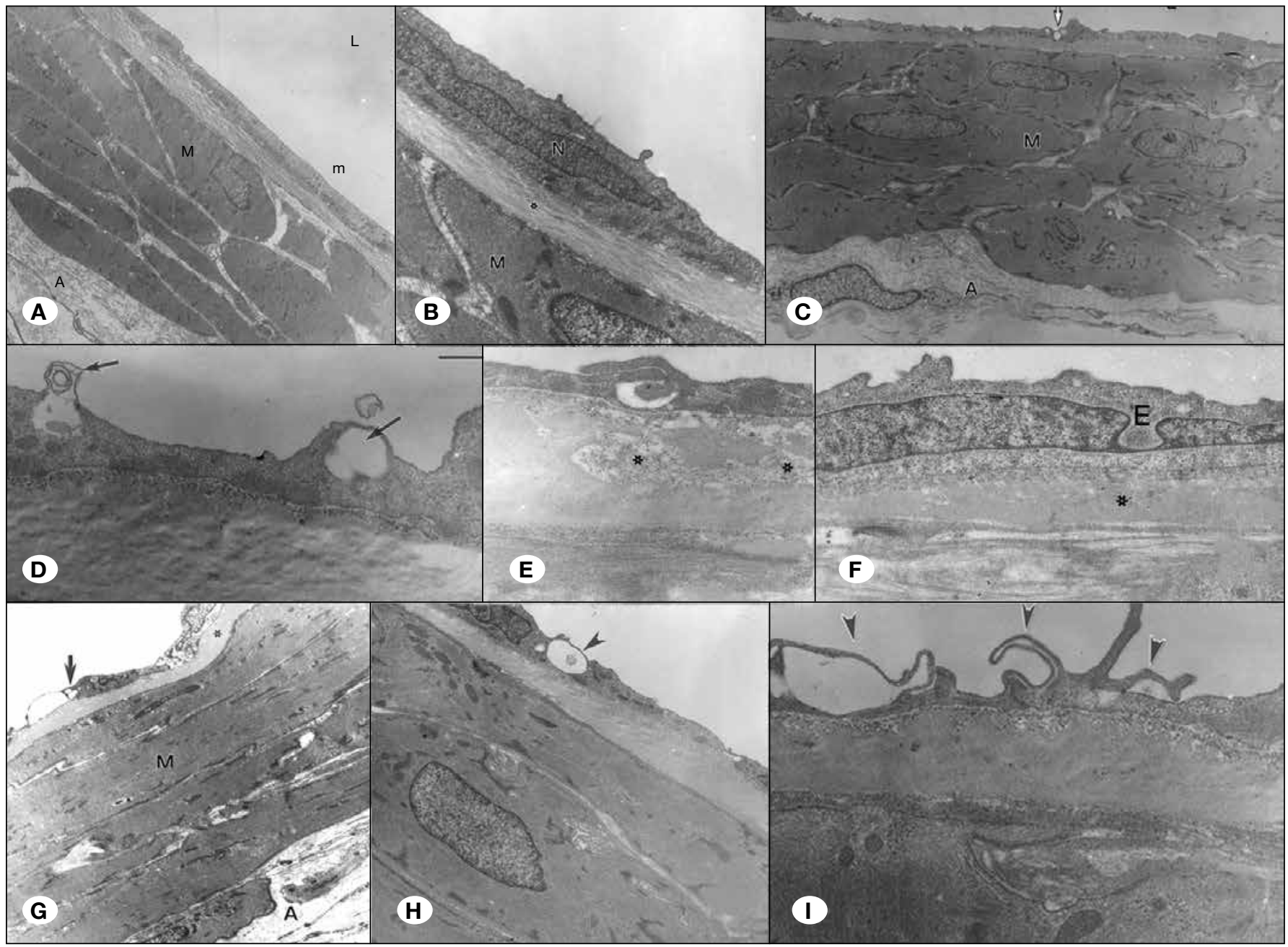

Figure 2: Group 1 A) Group 1: Basilar Artery Lumen (L), endothelial cells in tunica intima layer (E) and internal elastic membrane (asterisks), the shape of the smooth muscle cells in tunica media layer (M), nucleus and indigents of the cytoplasm and adventitia (A) seem to be normal with connective tissue. B) Group 1: In the higher magnification, endothelial cells (E) and internal elastic membrane (asterisks), smooth muscle cells in tunica media layer (M) were seen in the Basilar Artery. Group $\mathbf{3}$ C) Smooth muscle cells in the tunica media layer (M) and adventitia layer seem to be normal but the vacuolization (arrow) in endothelial cells in the tunica intima layer was seen. D) Huge vacuolization with lamellar myelin figures (arrow) in endothelial cells, E) Loosening type degenerative changes in the internal elastic membrane layer (asterisks) F) Irregular extensions in endothelial cells (arrows); irregularity and irregular extension of endothelial cells and tight, irregular and flat extensions between the endothelial cells. Group 2 G) Highly degenerated endothelial cells; pro-apoptotic and pro-necrotic endothelial cells (arrow). H) Endothelial cells with huge vacuolization (arrow) I) Endothelial cells with normal formation and (E) and internal elastic membrane (asterisks). 


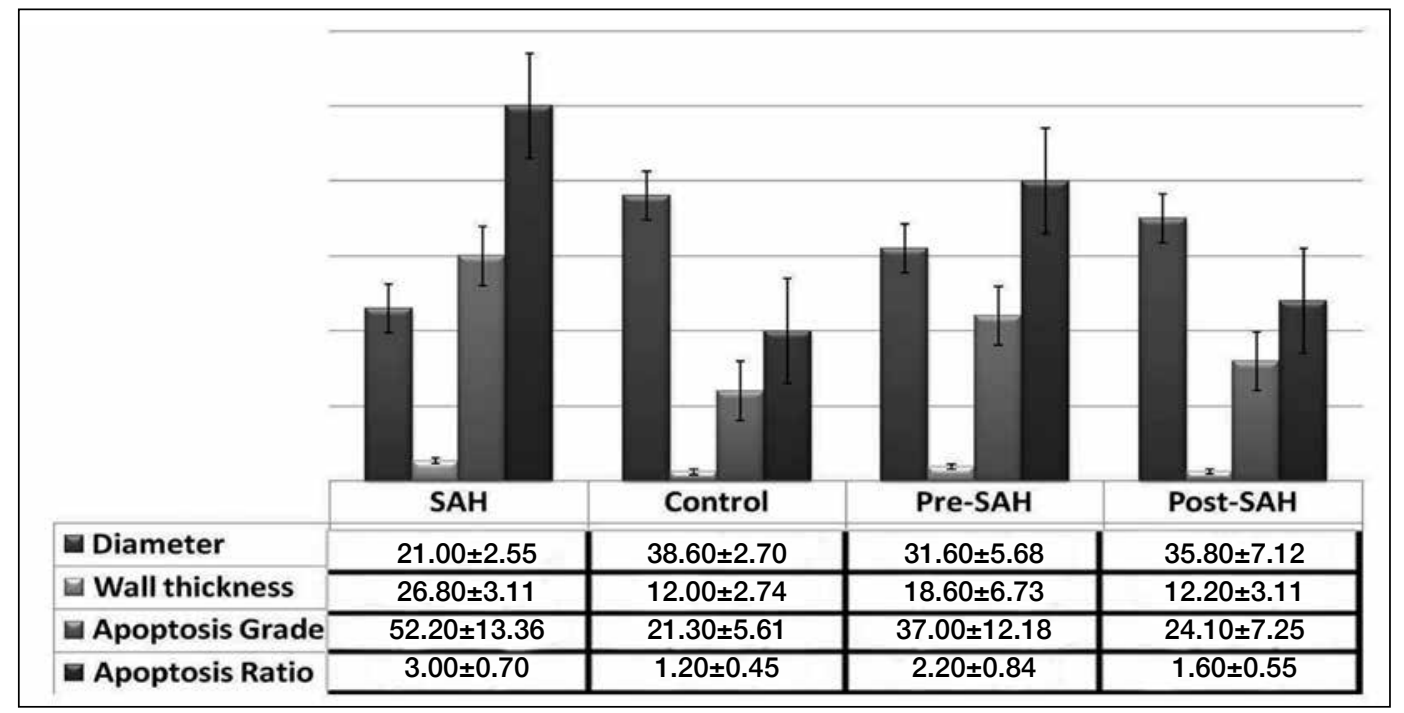

Figure 3: The

measurements of luminal diameters, arterial wall thickness, apoptosis ratio and grading. antioxidant, anti-inflammatory, anti-ulcer, and anti-diarrheal activities were described (12).

Taken together, these studies demonstrate that grape seed proanthocyanidin extract (GSPE) is a bio-available and potent free radical scavenger, and exhibits novel cardioprotective properties. The novel mechanistic pathways of cardioprotection exerted by GSPE include: (i) potent hydroxyl and other free radical scavenging abilities; (ii) antiapoptotic, anti-necrotic, and anti-endonucleolytic potentials; (iii) modulatory effect on apoptotic regulatory bcl-XL, p53, and c-myc genes; (iv) cytochrome P450 2E1 inhibitory activity; (v) inhibitory effects on adhesion molecules; (vi) modulatory effects on proapoptotic and cardioregulatory genes c-JUN, JNK-1, and CD36 (3). Electron microscopy of the treatment group and TUNEL staining of all groups with significant different rates of apoptosis of the arterial wall showed the antioxidant-antiapoptotic-antinecrotic effect of PR.

NO can exert a variety of biological activities in various physiological and pathological conditions. As a free radical, NO has been shown to play a double-edged role in the regulation of apoptosis. It can be either pro-apoptotic or antiapoptotic, depending on the type of cell, the location, the timing and the amount produced (40). Recent studies have shown that GSPE increases NO by activating the inducible NOS (iNOS) (31). The vasodilator effect of PR was shown in pre- and post-treatment groups.

PRs have been shown to have effects on the cardiovascular system. They upregulate the activity and expression of superoxide dismutase, and have antioxidant activity and ability to augment the antioxidant potential of plasma in rats $(6,9,20)$. They augment the biological activity of nitric oxide (NO) and NO synthase expression (33).

We demonstrated the vasodilator effect of PR in the pretreatment and post-treatment group with significant difference of arterial diameter with respect to $\mathrm{SAH}$ group. There was no significant difference with respect to the control group. An antioxidant effect was shown with electron-microscopical findings of the structural investigation of the arterial walls of the groups. There were milder findings of pathological changes due to vasospasm in the treatment group with respect to the vasospasm group (Figures 2D-I).

Endothelial vasodilation has been extensively studied and found to be controlled mainly by NO, prostacyclin, and endothelium derived hyperpolarizing factor (7).

DalBó et al., as a result of their study aiming to investigate the relaxing effects of a proanthocyanidin in the rat mesenteric arterial bed, found that this effect involves mainly the NOcGMP pathway and hyperpolarization induced by $\mathrm{KCa} 2+$ activation $(10,11)$.

Since PRs are found in the normal human diet, evaluation of their clinical efficacy for potential application for the prevention and treatment of cardiovascular diseases is important as this plant enhances endothelial function by formation of vasoprotective endothelial factors. In our study, we showed the protective effect of PR in the basilar artery by a lower apoptosis level of the basilar artery in the pre-treatment group.

\section{CONCLUSION}

Pre-SAH administration of PR induces better vasodilatation and protection of BA from VS, which could yield neuroprotective and vasodilatator effects. In addition, PR appears to be involved in relieving oxidative damage, with an antioxidantantiapoptotic-antinecrotic effect that may contribute to vascular dilation. Further studies are needed to confirm these results and to elucidate the possible biochemical mechanisms underlying the action of PR in preventing CV. 


\section{REFERENCES}

1. Andriambeloson E, Stoclet JC, Andriantsitohaina R: Mechanism of endothelial nitric oxide-dependent vasorelaxation induced by wine polyphenols in rat thoracic aorta. J Cardiovasc Pharmacol 33:248-254, 1999

2. Ayajiki $K$, Kindermann $M$, Hecker $M$, Fleming I, Busse R: Intracellular $\mathrm{pH}$ and tyrosine phosphorylation but not calcium determine shear stress-induced nitric oxide production in native endothelial cells. Circ Res 78:750-758, 1996

3. Bagchi D, Sen CK, Ray SD, Das DK, Bagchi M, Preuss HG, Vinson JA: Molecular mechanisms of cardioprotection by a novel grape seed proanthocyanidin extract. Mutat Res 523-524:87-97, 2003

4. Buckley BJ, Mirza Z, Whorton AR: Regulation of $\mathrm{Ca}(2+)-$ dependent nitric oxide synthase in bovine aortic endothelial cells. Am J Physiol 269:C757-765, 1995

5. Busse R, Luckhoff A, Winter I, Mulsch A, Pohl U: Fendiline and calmidazolium enhance the release of endothelium-derived relaxant factor and of prostacyclin from cultured endothelial cells. Naunyn Schmiedebergs Arch Pharmacol 337:79-84, 1988

6. Chan P, Cheng JT, Tsai JC, Lien GS, Chen FC, Kao PF, Liu $\mathrm{JC}$, Chen YJ, Hsieh MH: Effect of catechin on the activity and gene expression of superoxide dismutase in cultured rat brain astrocytes. Neurosci Lett 328:281-284, 2002

7. Chauhan S, Rahman A, Nilsson H, Clapp L, MacAllister R, Ahluwalia A: NO contributes to EDHF-like responses in rat small arteries: A role for NO stores. Cardiovasc Res 57:207-216, 2003

8. Clark JF, Sharp FR: Bilirubin oxidation products (BOXes) and their role in cerebral vasospasm after subarachnoid hemorrhage. $J$ Cereb Blood Flow Metab 26:1223-1233, 2006

9. da Silva Porto PCAL, Laranjinha JAN, de Freitas VAP: Antioxidant protection of low density lipoprotein by procyanidins: Structure/ activity relationships. Biochem Pharmacol 66:947-954, 2003

10. DalBo S, Goulart S, Horst H, Pizzolatti MG, Ribeiro-do-Valle RM: Activation of endothelial nitric oxide synthase by proanthocyanidinrich fraction from Croton celtidifolius (Euphorbiaceae): Involvement of extracellular calcium influx in rat thoracic aorta. J Pharmacol Sci 107:181-189, 2008

11. DalBo S, Moreira EG, Brandao FC, Horst H, Pizzolatti MG, Micke GA, Ribeiro-do-Valle RM: Mechanisms underlying the vasorelaxant effect induced by proanthocyanidin-rich fraction from Croton celtidifolius in rat small resistance arteries. J Pharmacol Sci 106:234-241, 2008

12. De Bruyne T, Pieters L, Deelstra H, Vlietinck A: Condensed vegetable tannins: Biodiversity in structure and biological activities. Biochem Syst Ecol 27:445-459, 1999

13. Demura $\mathrm{Y}$, Ishizaki T, Ameshima S, Okamura S, Hayashi T, Matsukawa S, Miyamori I: The activation of nitric oxide synthase by copper ion is mediated by intracellular $\mathrm{Ca} 2+$ mobilization in human pulmonary arterial endothelial cells. $\mathrm{Br} \mathrm{J}$ Pharmacol 125:1180-1187, 1998

14. Dudzinski DM, Igarashi J, Greif D, Michel T: The regulation and pharmacology of endothelial nitric oxide synthase. Annu Rev Pharmacol Toxicol 46:235-276, 2006

15. Fleming I, Busse R: NO: the primary EDRF. J Mol Cell Cardiol $31: 5-14,1999$

16. Hansen-Schwartz J, Nordström CH, Edvinsson L: Human endothelin subtype A receptor enhancement during tissue culture via de novo transcription. Neurosurgery 50:127-136, 2002
17. Jens PD, Ebert N, Priller J, Megow D, Lindauer U, Klee R, Reuter U, Imai Y, Einhäupl KM, Victorov I, Dirnagl U: Products of hemolysis in the subarachnoid space inducing spreading ischemia in the cortex and focal necrosis in rats: A model for delayed ischemic neurological deficits after subarachnoid hemorrhage? J Neurosurg 93:658-666, 2000

18. Kassell NF: The role of vasospasm in overall outcome from aneurismal subarachnoid hemorrhage. In: Findlay JM (ed), Cerebral Vasospasm. Amsterdam: Elsevier, 1993:27-28

19. Kim I, Leinweber BD, Morgalla M, Butler WE, Seto M, Sasaki Y, Peterson JW, Morgan KG: Thin and thick filament regulation of contractility in experimental cerebral vasospasm. Neurosurgery 46:440-446, 2000

20. Koga T, Moro K, Nakamori K, Yamakoshi J, Hosoyama H, Kataoka $\mathrm{S}$, Ariga T: Increase of antioxidative potential of rat plasma by oral administration of proanthocyanidin-rich extract from grape seeds. J Agric Food Chem 47:1892-1897, 1999

21. Macdonald RL, Weir B: Cerebral vasospasm: Prevention and treatment. Philadelphia: Lippincott-Raven, 1997

22. Macdonald RL, Weir BK: A review of hemoglobin and the pathogenesis of cerebral vasospasm. Stroke 22:971-982, 1991

23. Martin S, Andriambeloson E, Takeda K, Andriantsitohaina R: Red wine polyphenols increase calcium in bovine aortic endothelial cells: $\mathrm{A}$ basis to elucidate signalling pathways leading to nitric oxide production. Br J Pharmacol 135:1579-1587, 2002

24. McGirt MJ, Woodworth GF, Pradilla G, Legnani F, Warner D, Tamargo R, Clatterbuck R, Lynch JR, Laskowitz DT: Galbraith Award: simvastatin attenuates experimental cerebral vasospasm and ameliorates serum markers of neuronal and endothelial injury in patients after subarachnoid hemorrhage: A dose-response effect dependent on endothelial nitric oxide synthase. Clin Neurosurg 52:371-378, 2005

25. Ohkuma $\mathrm{H}$, Tsurutani $\mathrm{H}$, Suzuki S: Changes of beta-actin mRNA expression in canine vasospastic basilar artery after experimental subarachnoid hemorrhage. Neurosci Lett 311:9-12, 2001

26. Ostrowski RP, Colohan AR, Zhang JH: Molecular mechanisms of early brain injury after subarachnoid hemorrhage. Neurol Res 28:399-414, 2006

27. Peter V, Meyer B, Weidauer S, Raabe A, Thome C, Ringel F, Breu V, Schmiedek P: Clazosentan (AXV-034343), a selective endothelin A receptor antagonist, in the prevention of cerebral vasospasm following severe aneurysmal subarachnoid hemorrhage: Results of a randomized, double-blind, placebo-controlled, multicenter Phase lla study. J Neurosurg 103:9-17, 2005

28. Pluta RM: Delayed cerebral vasospasm and nitric oxide: Review, new hypothesis, and proposed treatment. Pharmacol Ther 105:23-56, 2005

29. Prunell GF, Svendgaard N-A, Alkass K, Mathiesen T: Inflammation in the brain after experimental subarachnoid hemorrhage. Neurosurgery 56:1082-1092, 2005

30. Rasmussen SE, Frederiksen H, Struntze Krogholm K, Poulsen L: Dietary proanthocyanidins: Occurrence, dietary intake, bioavailability, and protection against cardiovascular disease. Mol Nutr Food Res 49:159-174, 2005

31. Roychowdhury S, Wolf G, Keilhoff G, Bagchi D, Horn T: Protection of primary glial cells by grape seed proanthocyanidin extract against nitrosative/oxidative stress. Nitric Oxide 5:137-149, 2001 
Yilmaz C. et al: Proanthocyanidin in SAH

32. Santhanam AVR, Smith LA, Akiyama M, Rosales AG, Bailey KR, Katusic ZS: Role of endothelial NO synthase phosphorylation in cerebrovascular protective effect of recombinant erythropoietin during subarachnoid hemorrhage-induced cerebral vasospasm. Stroke 36:2731-2737, 2005

33. Sato M, Maulik G, Ray PS, Bagchi D, Das DK: Cardioprotective effects of grape seed proanthocyanidin against ischemic reperfusion injury. J Mol Cell Cardiol 31:1289-1297,1999

34. Sehba FA, Bederson JB: Mechanisms of acute brain injury after subarachnoid hemorrhage. Neurol Res 28:381-398, 2006

35. Shimoda M, Takeuchi M, Tominaga J, Oda S, Kumasaka A, Tsugane R: Asymptomatic versus symptomatic infarcts from vasospasm in patients with subarachnoid hemorrhage: Serial magnetic resonance imaging. Neurosurgery 49:1341-1348; discussion 1348-1350, 2001

36. Solomon RA, Antunes JL, Chen RY, Bland L, Chien S: Decrease in cerebral blood flow in rats after experimental subarachnoid hemorrhage: A new animal model. Stroke 16:58-64, 1985
37. Suarez JI, Tarr RW, Selman WR: Aneurysmal subarachnoid hemorrhage. New Engl J Med 354:387-396, 2006

38. Tani E, Matsumoto T: Continuous elevation of intracellular $\mathrm{Ca} 2+$ is essential for the development of cerebral vasospasm. Curr Vasc Pharmacol 2:13-21, 2004

39. Vatter H, Weidauer S, Konczalla J, Dettmann E, Zimmermann M, Raabe A, Preibisch C, Zanella FE, Seifert V: Time course in the development of cerebral vasospasm after experimental subarachnoid hemorrhage: Clinical and neuroradiological assessment of the rat double hemorrhage model. Neurosurgery 58:1190-1197, 2006

40. Wink DA, Mitchell JB: Chemical biology of nitric oxide: Insights into regulatory, cytotoxic, and cytoprotective mechanisms of nitric oxide. Free Radic Biol Med 25:434-456, 1998

41. Zhang $\mathrm{H}$, Weir $\mathrm{B}$, Marton LS, Macdonald RL, Bindokas V, Miller RJ, Brorson JR: Mechanisms of hemolysate-induced [Ca2+] elevation in cerebral smooth muscle cells. Am J Physiol 269(6 Pt 2):H1874-1890, 1995 